УДК 811.161.1'1

ББК 81.411.2

DOI: https://doi.org/10.17308/lic.2020.4/3089

\title{
ЛИНГВОКОГНИТИВНАЯ МОДЕЛЬ ПОСТУПКА «ДЕРЗОСТЬ»
}

\author{
Л. А. Бушуева \\ Нижегородский государственный университет имени Н. И. Лобачевского
}

THE LINGUO-COGNITIVE MODEL OF AN IMPUDENT ACT

\author{
L. A. Bushuyeva \\ Lobachevsky State University of Nizhny Novgorod
}

\begin{abstract}
Аннотация: данное исследование посвящено анализу русских лексем, обозначающих ситуацию поступка «дерзость» с точки зрения когнитивной и прототипической семантики, а также теории фреймов. $B$ работе основное внимание уделяется дерзости как поступку. Под поступком понимается сознательное и разумное действие человека, совершающееся в результате реализачии мотива и вызывающее определенную реакиию у окружающих, выражающуюся в виде оценки. В основе исследования лежит гипотеза о том, что понятие поступка «дерзость» опирается на фрейм, представляющий собой структуру, состоящую из слотов: мотив поступка, действие как проявление поступка, агент, объект, результат, оиенка поступка. Целью исследования является показать, каким образом и в каком объеме данные слоты актуализированы на системно-языковом уровне, на синтаксическом уровне, на уровне речи и уровне вербальных ассоциаций. На основании лексикографического анализа, анализа семантических ролей, выраженных именем поступка «дерзость», а также его актантами, контекстуального и ассоииативного анализов была построена лингвокогнитивная модель ситуации поступка «дерзость». Проведенное исследование позволило выявить прототипические содержательные признаки слотов фрейма «дерзость».

Ключевые слова: имя поступка, фрейм, слот, прототип, семантическая роль.
\end{abstract}

\begin{abstract}
Russian lexemes, naming the situation of the impudent act, from the cognitive and prototype semantics, as well as the frame theory. In this article impudence is viewed as an act. An act is understood by the author as an intended action, that is committed by a human being, leads to a certain result and valued by another person or people. The research is based on the idea that notions about some acts, including the act of impudence, rely on the frame which is a structure, the elements of which are the motive, the action, the subject of the act, its object, the result and the value. The aim of the paper is to show how these elements are represented on the language level, on the syntactic level, on the level of speech and the level of verbal associations. The lexicographic analysis, the analysis of the semantic roles, expressed by the name of the act of impudence and its actants, the discourse analysis and the study of the associative data helped to come up with the linguo-cognitive model of the impudent act. The prototypic features of the frame were figured out as well. Key words: the name of act, frame, slot, prototype, semantic role.
\end{abstract}

\section{Введение}

Поступок выступает формирующим фактором бытия, специфическим проявлением жизни человека. Поступок - «это всякое действие человека, в котором принимает участие его организм и за которое он чувствует себя ответственным (в отличие от рефлективных движений)» [1]. В поступке особо подчеркивается, что он принадлежит сфере нрав- ственности. Это и является основным отличием поступка от действия. Важным отличием поступка от действия является также то, что поступок всегда так или иначе соотнесен с окружающими, так как он всегда имеет значение для других. Действие же может быть направлено на достижение какой-то цели, но зачастую не имеет никакого отношения к окружающим.

(C) Бушуева Л. А., 2020

Контент доступен под лицензией Creative Commons Attribution 4.0 License.

The content is available under Creative Commons Attribution 4.0 License. 
С. В. Димитрова, исследуя соотношение действия и поступка, приходит к выводу, что: 1) поступок следует рассматривать как ценностную характеристику действия, поскольку человек оценивает, какое влияние окажут его действия на других людей; 2) поступок базируется на чувстве долга, которое служит основанием для целей; 3) условием для поступков является существующее бытие человека, которое реализуется в результате свершения поступков; 4) человек обретает нравственную характеристику (становясь хорошим или плохим) лишь в процессе совершения поступков - судить о человеке можно по его поступкам, соотнося их с нравственной оценкой, устанавливаемой совестью [2].

На принципиальную разницу между понятиями «поступок» и «действие» указывают и типичные сочетаемостные характеристики лексемы поступок и единиц, обозначающих поступки. Ср.: решиться / отважситься на + поступок / измену / подлость; идти на + поступок / обман / подлость; надувательство / интрига / обман + раскрыться. Подобные сочетания маркируют значимость и оцениваемость, осознанность и целенаправленность соответствующих действий: «решиться - обдумав все за и против, преодолев боязнь ошибиться, убедить себя в целесообразности какого-либо действия, поступка» [3, с. 1018]; «идти на что-либо - соглашаться, решаться на какоелибо рискованное, трудное, неприятное и т. п. действие, проявлять готовность к осуществлению такого действия» [там же, с. 371]; «раскрыть - обнаружив что-либо недопустимое или преступное и при этом тщательно скрываемое, сообщить об этом» [там же, c. 684].

Таким образом, понятие «поступок» следует рассматривать как отличное от понятия «действие»: «поступок» - социально значимое действие.

В русском языке выделяется целая группа имен существительных, которые можно причислить к именам поступков: предательство, благодеяние, геройство, проделка, безрассудство и др. Некоторые из подобных лексем могут использоваться для обозначения: 1) свойства; 2) поступка по данному свойству. Ср.: «глупость - недостаток ума, несообразительность; глупый поступок, глупая мысль» [4]. К группе таких лексем относится и существительное дерзость: «дерзость - оскорбительная непочтительность, грубость; дерзкий поступок, дерзкие слова» $[5$, c. 150$]$.

В фокусе данного исследования находится второе значение лексемы дерзость, а именно «дерзкий поступок». Значения «оскорбительная непочтительность, грубость», «вызывающе смелые, пренебрегающие опасностью, слова, высказывания», также свойственные лексеме дерзость, в данном исследовании не рассматривались.

\section{Материалы и методы}

Целью данного исследования является изучение особенностей категоризации знаний о поступке «дерзость» и построение на этой основе общей лингвокогнитивной модели (фрейма) данного поступка. Фрейм - средство представления когнитивной структуры, «когнитивная модель, передающая знания об определенной стереотипной ситуации» [6, с. 29]. Фрейм - это всегда структурированная единица знания, в которой выделяются компоненты и связи между ними. В основе понятия «лингвокогнитивное моделирование» лежит представление о том, что поступающая к человеку информация извне не только непосредственно воспринимается, но и сложнейшим образом обрабатывается. Полученная информация становится объектом дальнейших ментальных, в частности познавательных, процессов. В большинстве этих процессов участвует язык.

Поступок «дерзость» изучается в его когнитивной организации и языковом оформлении на материале русского языка. Сложность изучения этических концептов требует применения целого комплекса процедур, что, в целом, согласуется с современными исследованиями, в основе которых лежит системность описания. Мы разделяем позицию Ю. Д. Апресяна, согласно которой «реконструкция каждого фрагмента картины мира считается мотивированной тогда, когда реконструированный фрагмент подтверждается не разрозненными данными, а большой совокупностью фактов, позволяющих построить цельный и непротиворечивый образ объекта» [7, с. 349]. Итак, лингвокогнитивная модель поступка «дерзость» строится на основании следующих видов анализа.

1. Семантический анализ. На материале лексикографических источников выявляется то, каким образом поступок репрезентирован в лексической системе языка. Семантический анализ является необходимым преддверием к анализу концептуальному, так как он представляет исследователю тот материал, который подлежит дальнейшей аранжировке в составе концептуальной модели. Системно-языковые данные позволяют воссоздать каркас соответствующей фреймовой модели.

2. Анализ семантических ролей, выраженных в контекстах с именем-репрезентантом поступка. Анализ семантических ролей призван показать, каким образом семантика ситуации распределяется по синтаксической структуре, выявить в текстах элементы фрейма и способы их выражения. Источником контекстуального материала послужил Национальный корпус русского языка (далее - НКРЯ) [8].

3. Анализ контекстуального поведения единиц, репрезентирующих фрейм рассматриваемого поступка. Данный анализ нацелен на верификацию результатов предшествующих исследований, достраивание 
полученного фрейма, уточнение его содержательного наполнения, определение актуальности его слотов, выделение прототипических признаков его содержания.

4. Анализ вербальных ассоциаций. Данный вид анализа является значимым критерием объективации прототипических содержательных компонентов. Прототипичность проявляется в том единодушии, с которым носители языка характеризуют значение определенных единиц в отрыве от контекста. Анализ вербальных ассоциаций проводился на материале «Русского ассоциативного словаря» [9].

\section{Результаты исследования}

Дерзость представлена в лексикографических источниках, как «1. непочтительный, грубый, вызывающий поступок; 2. вызывающе смелый, пренебрегающий опасностью поступок» [4]; «поступок, обнаруживающий непочтительность, грубость» [10]; «определяется не рассудком, а внезапно возникшим желанием стать равным высшему по духу, уму или физической силе; в отличие от отваги заключается в духовном посягательстве на что-либо высшее» [11]. Ситуация поступка «дерзость» может получать выражение не только через имя дерзость, но и с помощью единиц дерзкий (дерзкий поступок), дерзко (поступить дерзко). Ср.: «дерзкий - вызывающе смелый, пренебрегающий опасностью, возможным сопротивлением, противодействием» [12]. Сема «смелый» является основополагающим элементом в структуре понятия «дерзость», на что указывают многочисленные определения, в том числе включая описания, представленные в этимологических словарях: «дерзкий - от дьрзъ - смелый, решительный до грубости» [13]; а также словарях синонимов: «дерзость - 1. смелость; 2. непочтительность» [14]. При этом смелость, лежащая в основе дерзости, определяется как вызывающая, т. е. оскорбляющая общепринятые нормы, содержащая некий вызов.

Рассмотренные дефиниции лексем дерзость, дерзкий, дерзко дают возможность выделить в содержании ситуации поступка «дерзость» следующие признаки: 1) поступок человека; 2) смелый; 3) противоречащий общепринятым нормам; 4) мотивированный психоэмоциональным состоянием агента.

Если поступок «дерзость» представить в виде фрейма, то данный фрейм в лексической системе русского языка представлен лишь одним слотом, а именно слотом «Оценка поступка, агента поступка», репрезентантами которого являются лексемы дерзкий, дерзко. В лексической системе русского языка вербально не закреплены представления об агенте дерзости, действии, мотиве или результате, т. е. отсутствуют лексемы, специализированные на обозначении названных актантов ситуации дерзкого поступка.
Фрейм ассоциируется не только с набором лексем, употребленных в определенном лексическом значении, но и с набором лексических конструкций каждой из этих лексем. Конструкции представляют то или иное подмножество обозначаемых участников фрейма, с одной стороны, и формальный способ их выражения - с другой.

Вслед за И. В. Евсеевой и Г. Е. Крейдлиным полагаем, что слоты образуют пропозициональные структуры, в основе которых лежит предикат с его актантами [15, с. 9]. При построении пропозициональных структур необходимо фиксировать минимальное число компонентов (предикат и его актанты), без которых невозможно понять смысл лексемы.

В ходе анализа были выделены основные семантические роли, которые наиболее регулярно эксплицированы в речевых выражениях с именем поступка «дерзость». За основу исследования семантических ролей, актуализированных в контекстах с лексемой дерзость, был взят инвентарь семантических ролей, приведенный в [16].

Как показал проведенный анализ, фрейм поступка «дерзость» представлен в текстах НКРЯ следующими семантическими ролями: «Агенс», «Пациенс», «Предмет мысли», «Причина», «Мотивировка», «Время».

К семантическим ролям, выражаемым именем дерзость, относятся роли «Мотивировка», «Причина».

Семантическая роль «Мотивировка» подразумевает действие, состояние, свойство, положение вещей, объясняющее, почему агентивный участник предпринял действие, но не являющееся его причиной. Наиболее типичным способом выражения данной роли в тексте является обстоятельство причины:

Tы отвратительно и оскорбительно повела себя на форуме по отношению ко мне. $\underline{3 а}$ твою дерзость я могу тебя удалить, но дабы ты ждешь других мнений от других людей, я не стану тебя удалять (коллективный. Форум: помогите пожалуйста! Расскажите про СИЗО № 4).

Типичной ситуацией, в которой поступок «дерзость» выступает мотиватором, является ситуация наказания. Выполняя роль мотива в ситуации наказания / возмездия, имя поступка характеризуется отрицательной оценкой (наказать / разжаловать / удалить / поставить к стенке / отомстить за дерзость).

В следующем контексте дерзость мотивирует мнение о том, что последует наказание:

- Гуляй, гуляй, мильй, пока тебе не накостыляли за дерзость. Все это происходило возле трамвайной остановки, на глазах многих людей (А. Савельев, Аркан для бумеранга).

Поступок «дерзость» является причиной некоторых ситуаций или обусловливает возникновение 
состояния. Данная роль часто выражена при глаголах психологического состояния (волноваться, беспокоиться, тосковать, стылиться). В текстах НКРЯ дерзость представлена как причина разных состояний одного из участников ситуации, включая самого агента поступка: испуга / волнения / замешательства / неловкости / злости.

Ему было лет восемь, когда он провинился $и$, боясь гнева дедушки, не пошел кланяться ему в ноги, а спрятался на чердаке. Дедушка от такой дерзости рассвирепел (Е. Есенина, В Константинове);

А когда «позор» прошел и осталась только память о моей дерзости, я стала чувствовать легкий ореол вокруг себя, ихотя это было приятное чувство, но мне все-таки продолжало быть стыдно до самого лета (Н. Берберова, Курсив мой).

Для актантов имени дерзость наиболее характерными являются семантические роли «Агенс», «Пациенс», «Предмет мысли», «Время».

Наиболее продуктивными в плане выражения «Агенса» являются следующие конструкции:

1) имя нарицательное, собственное или личное местоимение в позиции субъекта (в Им. п.):

От неожиданности столичный генерал-губернатор решается на единственно спасительную дерзость (А. Архангельский, Александр I);

Mbl, студенты, занятые в "Слуге двух господ», пошли на несльханную дерзость, на отчаянный шаг: больше не пустим Марию Ивановну на репетиции до самого показа ни разу! (В. Розов, Удивление перед жизнью);

2) имя нарицательное, собственное или личное местоимение в позиции субъекта (в Т. п.):

Через полгода после «принятия присяги» родной комсомол расстался со мной по первому разряду, отлучив меня на три недели от себя, хотя мною не было совершено ни одного проступка, даже дерзости (В. Аграновский, Вторая древнейшая. Беседы о журналистике);

3) имя нарицательное, собственное или личное местоимение в позиции дополнения (в Р. п.):

Но такой дерзости ждать от Юрия Лужкова не приходится (Н. Зверева, Начался процесс по иску заложников «Норд-оста»); Д. п.):

4) личное местоимение в позиции дополнения (в

Мало того, вскоре четко обозначил свою позицию, позволив себе вопиюшую для правоверного мусульманина дерзость: приговорил к смертной казни самого муфтия Чечни А. Кадырова (Г. Трошев, Моя война);

$5)$ притяжательное прилагательное или местоимение в адъективной позиции, при этом синтаксическая функция - определение:

Особенное осуждение и классного наставника, $u$

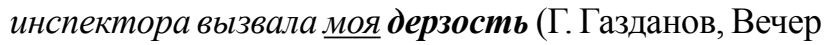
у Клэр).
Роль «Пациенс», предполагающая участника ситуации, претерпевающего самопроизвольно или под воздействием другого участника изменения, не часто получает актуализацию в контекстах, описывающих дерзкие поступки. Немногочисленные контексты указывают на то, что данная роль получает выражение в основном через имя собственное, нарицательное или местоимение (в Д. п.) в функции дополнения:

От его дерзостей может доставаться и властям, и вельможам; он мастер пародии, доходящей до кошунства, когда предметом выходок может стать ичерковная служба (и даже само Священное писание!) (О. Чайковская, Великий царь или Антихрист).

«Предмет мысли», то, о чем думает, о чем знает какие-либо факты «Субъект ментального состояния», также может актуализироваться в предложениях, содержащих единицу дерзость. «Предмет мысли» может получать выражение через обороты с глаголами интеллектуальной деятельности (помнить, счиmamb и др.) в конструкциях с прямым дополнением.

Я краснею при воспоминании о моей дерзости семь лет тому назад (А. Куприн, Гранатовый браслет);

По армейскому этикету того времени бросать оружие под ноги считалось немьслимой дерзостью, нарушением воинского долга (О. Пчелов, В драгуны не вышел, а шапки шить стал).

Роль «Время» крайне редко получает выражение в контекстах с лексемой дерзость, при этом «Время» обычно актуализировано в рамках обстоятельства времени:

По тем временам передача рукописи иностраниу была поступком неслыханной дерзости (Е. Евтушенко, Волчий паспорт).

В ходе исследования фреймовой структуры поступка «дерзость» в текстах НКРЯ были дифференцированы контексты, в которых имя дерзость обозначает поступок и контексты, в которых данная лексема именует свойство, результатом которого является поступок. Имя дерзость обозначает поступок в 13,8 \% от всех рассмотренных с данной лексемой контекстов; в 3,4% контекстов является номинацией свойства, результатом которого является поступок; остальные контексты из рассмотренного числа (всего 350 контекстов) не имеют отношения к ситуации поступка. Ср.:

А самым удивительнылм было то, что эту войну вызвал Хадко. Старики видели в том мальчитескую глупость, смешанную с необузданной дерзостью. Но то, что Мэбэт одобрил выходку сына, поднимало в их душах мутное предчувствие (А. Григоренко, Мэбэт);

Только единожды, набравшись дерзости, она переступила порог настоящего журнала (Ш. Шалит, Свободная душа Эсфири Фридзель); 
Ведь для этого во время самой страшной пурги нужно выйти из дома, встать на открытое, незащишенное место и обратиться $к$ стихии лииом... Только отчаянного безумияа, решившегося на эту дерзость, пурга наградит необычайным, ни с чем не сравнимым ароматом, соединивиим влажные запахи северного моря со свежим дыханием прибрежной mундры (В. Писигин, Письма с Чукотки);

После матча Улье скажет, что атаке его команды «не хватало дерзости» (Д. Навоша, Дьявольское везение // «Известия»);

- Я напишу твоей маме, что ты говоришь мне дерзости (Г. Газданов, Вечер у Клэр).

Первые два контекста являются иллюстрацией использования имени дерзость для обозначения свойства, результатом которого стал поступок. Третий контекст - пример функционирования лексемы дерзость в качестве имени поступка. В четвертом и пятом контекстах ситуация поступка не актуализирована. Контексты такого плана в данном исследовании не рассматривались.

Сложность структуры фреймов, трудность определения границ между ними требуют рассмотрения этого понятия сквозь призму теории прототипов. В этом случае фрейм интерпретируется как сущность, в основе которой лежит какая-то норма, прототип, формирующий модель ситуации, которая распознается как эталонная и является основой для сравнивания, сопоставления с ней других ситуаций, возникающих в опыте.

По словам А. Е. Бочкарева, образец, избираемый в качестве прототипа, отвечает критерию «максимальной информации», так как характеризуется по сравнению с «нетипичными» представителями категории наибольшим числом прототипических признаков. В этом заключается «принцип когнитивной экономии» [17, с. 251].

Материалы НКРЯ свидетельствуют о том, что в речи конкретизированы 6 слотов фрейма «дерзость»: «Агент поступка», «Мотив поступка», «Действие как проявление поступка», «Оценка поступка», «Объект поступка» и «Результат поступка».

Всего было проанализировано более тысячи контекстов НКРЯ (по 350 контекстов на каждую из лексем дерзость, дерзкий, дерзко). Исследование показало, что в наибольшей степени в русской речи актуализированы слоты «Агент поступка» $(10 \%$ от всех контекстов) и «Действие как проявление поступка» (7,7 \% контекстов); в 3,4 \% всех контекстов выражен слот «Результат поступка»; приблизительно в равной степени актуализированы слоты «Оценка поступка» $(1,5 \%)$ и «Объект поступка» $(1,2 \%)$; лишь в $0,4 \%$ контекстов представлен «Мотив поступка».

В ходе исследования текстового материала НКРЯ нам удалось выявить прототипические для поступка «дерзость» признаки.
Слот «Агент поступка». Дерзость, судя по контекстам НКРЯ, может быть совершена любым человеком, независимо от возраста, пола, социального положения. Ключевым признаком, объединяющим всех агентов дерзких поступков, является смелость (иногда экстремальная, граничащая с нездоровой), которая может быть свойственна агенту в целом и/или проявляется в определенной ситуации под воздействием разных факторов (частотные словосочетания с именем дерзость - решиться на дерзость, отважсться на дерзость).

Да и вряд ли Ксафонов решился бы на такую дерзость, кишка у него тонка (Н. Дежнев, Принцип неопределенности);

- Меркин был против, чтобы я приглашал тебя, - сказал Иезибальд, отдыниавиись.

- Говорит, что ты сумасшедший и можешь повести себя дерзко, так? (С. Осипов, Страсти по Фому. Книга вторая).

В контекстах подчеркивается, что данный поступок требует определенного состояния духа и/или некой доли решимости, которые могут быть вызваны особыми обстоятельствами в жизни агента.

Человеку, которому на Рождество даже позвонить некому, кроме агента ФБР, охотящчегося за ним, естественно нечего терять, а это прямой путь к самым авантюрным и дерзким поступкам (коллективный. Форум: Рецензия на фильм «Поймай меня, если сможешь»);

$<\ldots>$ мальчишка не переборол еще себя, парень не взял над ним власти - возраст перепутный, неустойчивыц. В эти годы парни, да и девки тоже, совершают больше всего дерзостей, глупостей и отчаянных поступков (В. Астафьев, Царь-рыба);

Театр, однако, не поработил Чехова. Покорил да, но не поработил; он чувствовал себя в нем настолько вольно, что позволял себе разные дерзости (Р. Киреев, Чехов. Посещение Бога).

Слот «Действие ка проявление поступка». Данный слот также получает регулярную экспликацию в контекстах НКРЯ. Прототипическими действиями, которые причисляются к дерзости, являются: 1) действия, нарушающие общепринятые правила; 2) действия, сопряженные с риском.

Однако сидевший за рулем иномарки 26-летний Автандил Тодуа, вместо того чтобы остановить и вернуть украденное, рванул по разделительной на скорости 150 км/ч. За такую дерзость миличиионеры решили продырявить ему колеса и пустились в погоню (Новости, Автопилот);

Значит, предстояло придумать нечто такое, что станет неожиданностью для немцев и поможет одержать победу. Командование бригады решилось на дерзкий шаг. Отряд партизан был переодет в немеикое обмундирование, получил немечкое оружие. Он входил в гарнизон днем, открыто, под видом по- 
лицейского подразделения, прибывмего в помощь прыганьскомугарнизону (Начальник разведки, Солдат удачи);

В кониуе девятнадияатого века в Баргузине уже проживало немало «политических» евреев, в том числе «бабушка русской револючии» Брешко-Брешковская, впоследствии совершивиая дерзкий, но неудавиийся побег (Д. Рубина, Медная шкатулка).

Наиболее типичные словосочетания с прилагательным дерзкий также указывают на противоправный характер действий в основе рассматриваемого поступка: дерзкий / -ая / -ое нападение / убийство / побег / кража / вызов / грабеж / налет / похищение / захват / террористический акт / преступление / ограбление / теракт / афера; дерзкий налетчик / преступник / убийа / клеветник.

Слот «Результат поступка». Типичный результат дерзости четко очерчен в контекстах НКРЯ - это наказание / возмездие.

У него больше всех двоек, дерзостей и проделок. Поэтому он чаше других сидит в кариере (А. Мариенгорф, Мой век, мои друзья и подруги);

Для него сущуествовала сейчас лишь дерзкая просительница, которую надо было как можно беспощзаднее казнить за дерзость (Г. Николаева, Битва в пути).

Ситуация прощения, которую также может мотивировать поступок «дерзость», также косвенно указывает на то, что дерзость обязательно предполагает наказание:

Гимназическое начальство, снисходительно пожурив беглеца, на первый раз простило дерзкую выходку «исключительно ввиду патриотических мотивов» (С. Аксентьев, Две судьбы, разделенные двумя веками).

Слот «Оценка поступка, агента поступка». Сочетаемостные характеристики лексемы дерзость, а также контексты НКРЯ указывают на прототипическую отрицательную оценку поступка: несльханная / непростительная / немыслимая / недопустимая / ужасная / непозволительная / беспредельная дерзость.

- Как вы смеете клеветать, Ипполит! Я никогда не допушу этого в моем доме! Какая возмутительная дерзость! Какая плебейская выходка! (Г. Газданов, Пробуждение);

В Египте приобщился он к гонителям ичеркви Христовой <...> и теперь помьшияет соединить Иудеев, гневом Божиим рассыланных по всему лииу земли, и устремить их на ниспровержение церкви Христовой и (о дерзость ужасная, превосходящая меру всех злодеяний!) на провозглашение лжемиссии в лииее Наполеона (Ф. Севастьянов, Ура! Теперь все можно?)

В редких контекстах дерзость имеет положительно-оценочный знак: $<\ldots>$ я, мальиш, решался, при всем своем обожании Францискевича, имитировать его повадки, амои родители, вообще такие дерзости не поошрявиие, в данном случае благодушно над моими имитациями потешались (А. Бенуа, Жизнь художника).

Слот «Объект поступка». Объект дерзкого поступка находит отражение в контекстах НКРЯ, но для него не выделяются какие-либо особые признаки объектом такого поступка может быть любой человек:

Владик, сын начальника тюрьмы Барбашина, рассказывал нам, явно со слов отияа, о крупных спекулянтах и самых настоящих, хорошо организованных жестоких бандах, наводивиих ужас дерзкими грабежами и убийством зажиточных граждан (Р. Ахмедов, Промельки);

Если ж, бесстыжее племя, певца вы обманете дерзко (М. Гаспаров, Занимательная Греция).

Слот «Мотив поступка». Как и любой поступок, дерзость также мотивирована чем-либо / кем-либо. Из контекстов НКРЯ очевидно лишь то, что в основе дерзкого поступка всегда лежит мотив, при этом специфических мотивов не выделяется:

В самом трагикомическом положении оказался Валя Непомнящий: назвать того, кто подвиг его на дерзкий поступок, он не мог уже потому, что был одним из авторов осуждаемого проекта (С. Рассадин, Книга прощаний. Воспоминания о друзьях и не только о них);

И самые свои дерзкие, самые лучиие свои поступки разве мужчины не ради женшин совершают? (Семикаракорский район, Приазовский край).

Ассоциативный материал в целом подтверждает выводы о содержательных признаках элементов фрейма поступка «дерзость», сделанные в ходе анализа системно-языковых и речевых данных. В РАС лексемы дерзость и дерзкий представлены в группе реакций на разные стимулы. Большинство стимулов актуализируют отрицательную оценку дерзости: дерзость

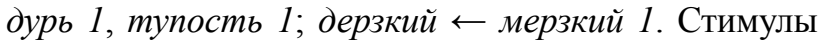
соотносят дерзость с отрицательными качествами:

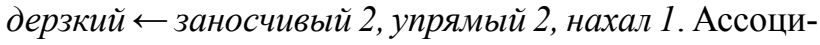
ативные данные также указывают на связь дерзости со смелостью: дерзость $\leftarrow$ смелость 1 .

\section{Заключение}

В целом анализ, проведенный на основе системно-языковых, корпусных и ассоциативных данных, позволяет уточнить определение поступка «дерзость». Дерзость - это отрицательно оцениваемый поступок человека, в основе которого лежит смелость / решимость (важно, что, в отличие от смелости, дерзость оценивается отрицательно: Когда человек смел - это хорошо, но если смелость становится дерзостью - жди беды (Ю. Рытхэу, Время таяния снегов), мотивированный различными факторами и 
воплощенный в действии, противоречащем общепринятым правилам поведения, сопряженном с риском, которое прямо / косвенно затрагивает другого человека и предполагает наказание. Фреймовая модель поступка представляет собой сочетание следующих элементов: «Агент поступка», «Мотив поступка», «Действие как проявление поступка», «Результат поступка», «Оценка поступка», «Объект поступка» (факультативный элемент). Ключевыми слотами, судя по степени их актуализации в системе языка, речи, ассоциативном материале, в семантико-ролевой структуре высказываний, являются слоты «Агент поступка», «Действие как проявление поступка», «Результат поступка».

\section{ЛИТЕРАТУРА}

1. Философский энциклопедический словарь. URL: https://terme.ru/slovari/filosofskii-enciklopedicheskiislovar.html

2. Димитрова С. В. Действия и поступки современного человека (аксиологический аспект рассмотрения) // Научные ведомости. 2013. № 23 (166), вып. 26. C. 205-215.

3. Большой универсальный словарь русского языка / под ред. В. В. Морковкина. М. : Словари XXI века, 2017. $1456 \mathrm{c}$.

4. Малый академический словарь русского языка. URL: http://www.classes.ru/all-russian/dictionary-russian-academ.htm

5. Толковый словарь русского языка / под ред. Д. Н. Ушакова. М. : ЛадКом, 2013. 848 с.

6. Болдырев Н. Н. Концептуальное пространство когнитивной лингвистики // Вопросы когнитивной лингвистики. Тамбов, 2004. № 1. С. 18-36.

7. Апресян Ю. Д. Интегральное описание языка и системная лексикография. М. : Школа «Языки русской культуры», 1995. 767 с.

8. Национальный корпус русского языка (основной и параллельный). URL: http://ruscorpora.ru/

9. Русский ассоциативный словарь / под ред. Ю. Н. Караулова [и др.]. М. : Астрель, 2002. Т. 1-2. $1776 \mathrm{c}$.

10. Большой толковый словарь русских существительных : Идеографическое описание. Синонимы. Антонимы / под ред. Л. Г. Бабенко. М. : АСТ-ПРЕСС КНИГА, 2005. 864 с.

11. Словарь русской ментальности / под ред. В. В. Колесова, Д. В. Колесовой, А. А. Харитонова. СПб. : Златоуст, 2014. Т. 1. 591 с.

12. Ефремова T. Ф. Новый толковый словарь русского языка. М. : Рус. яз., 2000. Т. 1-2. 1209 с.

13. Этимологический словарь русского языка / под ред. Н. М. Шанского. URL: https://exicography.online/ etymology/shansky/

14. Александрова 3. Е. Словарь синонимов русского языка. Практический справочник. URL: http://rus-yaz. niv.ru/doc/synonyms-aleksandrova/fc/slovar-196-1.htm\#zag-5915

15. Евсеева И. В., Крейдлин Г. Е. Фреймовое моделирование фрагментов лексико-словообразовательных гнезд с семантикой «заболевание» // Вестник Том. гос. ун-а. Филология. 2017. № 49. С. 5-23.

16. Кашкин Е. В., Лямевская О. Н. Семантические роли и сеть конструкций в системе FrameBank // Компьютерная лингвистика и интеллектуальные технологии : по материалам ежегод. Междунар. конф. «Диалог». М. : Изд-во РГГУ, 2013. Вып. 12 (19). С. 325-343.

17. Бочкарев A. E. Семантический словарь. Н. Новгород : Деком, 2003. 200 с.

\section{REFERENCES}

1. Filosofskij jenciklopedicheskij slovar' [Encyclopaedical dictionary of philosophy]. Available at: https://terme.ru/slovari/filosofskii-enciklopedicheskiislovar.html

2. Dimitrova S. V. Dejstvija i postupki sovremennogo cheloveka (aksiologicheskij aspekt rassmotrenija) [Acts and actions of a modern person (the aspect of evaluation)]. In Nauchnye vedomosti. 2013. No. 23 (166). Iss. 26. Pp. 205215.

3. Bol'shoj universal'nyj slovar' russkogo jazyka [The complete dictionary of the Russian language]. Ed. by V. V. Morkovkin. Moscow: Slovari 21 veka, 2017. 1456 p.

4. Malyj akademicheskij slovar' russkogo jazyka [The general purpose dictionary of Russian]. Available at: http:// www.classes.ru/all-russian/dictionary-russian-academ.htm

5. Tolkovyj slovar' russkogo jazyka [The Russian language dictionary]. Ed. by D. N. Ushakov. Moscow: «LadKom», 2013. 848 p.

6. Boldyrev N. N. Konceptual'noe prostranstvo kognitivnoj lingvistiki [The conceptual space of the cognitive linguistics]. In Voprosy kognitivnoj lingvistiki. Tambov, 2004. No. 1. Pp. 18-36.

7. Apresjan Ju. D. Integral'noe opisanie jazyka $i$ sistemnaja leksikografija [The integral analysis of a language and multi-faceted lexicography]. Moscow. Shkola «Jazyki russkoj kul'tury», $1995.767 \mathrm{p}$.

8. Russian language national corpus. Available at: http://ruscorpora.ru/

9. Russkij associativnyj slovar' [The Russian associative dictionary]. Ed. by Ju. N. Karaulova, G. A. Cherkasovoj, N. V. Ufimcevoj, Ju. A. Sorokina, E. F. Tarasova. M.: OOO «Izdatel'stvo Astrel'». Vol. 1-2. 2002. 1776 p.

10. Bol'shoj tolkovyj slovar' russkih sushhestvitel'nyh: Ideograficheskoe opisanie. Sinonimy. Antonimy [The dictionary of Russian nouns: ideographic description. Synonyms. Antonyms]. Ed. by L. G. Babenko. Moscow: ASTPRESS KNIGA, 2005. 864 p.

11. Slovar' russkoj mental'nosti [The dictionary of Russian mentality]. Ed. by V. V. Kolesova, D. V. Kolesovoj, A. A. Haritonova. Sankt Peterburg: Zlatoust. Vol. 1. 2014. $591 \mathrm{p}$. 
12. Efremova T. F. Novyj tolkovyj slovar' russkogo ja$z y k a$ [The modern dictionary of the Russian language]. Moscow: Rus. jaz. Vol. 1-2. 2000. 1209 p.

13. Jetimologicheskij slovar' russkogo jazyka [Etymology dictionary of the Russian language]. Ed by N. M. Shanskogo. Available at: https://lexicography.online/etymology/ shansky/

14. Aleksandrova Z. E. Slovar' sinonimov russkogo jazyka. Prakticheskij spravochnik [The dictionary of synonyms of the Russian language. A reference book]. Available at: http://rus-yaz.niv.ru/doc/synonyms-aleksandrova/ fc/slovar-196-1.htm\#zag-5915

15. Evseeva I. V., Krejdlin G. E. Frejmovoe modelirovanie fragmentov leksiko-slovoobrazovatel'nyh gnezd s

Нижегородский государственный университет имени Н. И. Лобачевского

Бушуева Л. А., доцент кафедры зарубежной лингвистики

E-mail: sebeleva@yandex.ru

Поступила в редакциию 29 апреля 2020 г.

Принята к публикаичи 25 сентября 2020 г.

\section{Для цитирования:}

Бушуева Л. А. Лингвокогнитивная модель поступка «дерзость» // Вестник Воронежского государственного университета. Серия: Лингвистика и межкультурная коммуникация. 2020. № 4. C. 139-146. DOI: https://doi. org/10.17308/lic.2020.4/3089 semantikoj «zabolevanie» [The frame modelling of the fragments of the derivational nets with the meaning "deseade"]. In Vestnik Tomskogo gosudarstvennogo universiteta. Filologija. 2017. No. 49. Pp. 5-23.

16. Kashkin E. V., Ljashevskaja O. N. Semanticheskie roli i set' konstrukcij v sisteme FrameBank [The semantic roles and the set of constructions in the Frame-bank system]. In Komp'juternaja lingvistika i intellektual'nye tehnologii: Po materialam ezhegodnoj Mezhdunarodnoj konferencii «Dialog». M.: Izd-vo RGGU, 2013. Iss. 12 (19). Pp. 325343.

17. Bochkarev A. E. Semanticheskij slovar' [The semantic dictionary]. Nizhnij Novgorod: Dekom, 2003. $200 \mathrm{p}$.

Lobachevsky University of Nizhny Novgorod

Bushuyeva L. A., Doctor of Philology, Associate Professor of the Foreign Linguistic Department

E-mail: sebeleva@yandex.ru

Received: 29 April 2020

Accepted: 25 September 2020

\section{For citation:}

Bushuyeva L. A. The linguo-cognitive model of an impudent act. Proceedings of Voronezh State University. Series: Linguistics and Intercultural Communication. 2020. No. 4. Pp. 139-146. DOI: https://doi.org/10.17308/ lic. $2020.4 / 3089$ 